\title{
On the action of carbon on metallic solutions
}

\section{Esprit}

To cite this article: M. Esprit (1850) On the action of carbon on metallic solutions, Philosophical Magazine Series 3, 37:250, 313-314, DOI: 10.1080/14786445008646611

To link to this article: http://dx.doi.org/10.1080/14786445008646611

册 Published online: 30 Apr 2009.

Submit your article to this journal

Џ Article views: 2

Q View related articles $₫$ 
the reaction of ammonia on the chlorides and bromides of the radicals of the alcohols. The following is a method of preparing ethyalmin, which probably possesses some advantages.

If the vapour of anhydrous sulphuric acid be absorbed by common æther, sulphuric æether, properly so called, or sulphatic æther $\left(\mathrm{C}^{4} \mathrm{H}^{5} \mathrm{O}, \mathrm{SO}^{3}\right)$ is formed, which, when water is added to it, remains dissolved in the excess of æther, from which it may be separated by spontaneous evaporation.

Sulphatic æether, treated with ammonia, acts like an anhydrous acid; it absorbs this base, and forms an ammoniacal salt of an amided acid. This new salt is represented by the formula $4 \mathrm{SO}^{3}, \mathrm{C}^{16} \mathrm{H}^{29}$ $\mathrm{NO}^{4}+\mathrm{NH}^{3} ; 4$ equivalents of the compound æther have absorbed 2 equivalents of ammonia, one of which has entered into the composition of the acid. On treating this salt with carbonate of barytes or of lead, ammonia is evolved, and barytic or lead salts are formed with the new acid, named by $M$. Strecker ethamic acid. This acid, treated with a hot solution of potash, yields ethyalmin, as proved by the analysis of the platina salt, which gave as its composition $\mathrm{C}^{4} \mathrm{H}^{7} \mathrm{~N}$, $\mathrm{H} \mathrm{Cl}, \mathrm{Pt} \mathrm{Cl}^{2}$; there are also formed alcohol and sulphuric acid.Comptes Rendus, Août 1850.

\section{ON THE ACTION OF CALBON ON METALIIC SOLUTIONS. BY M. ESPRIT.}

It is stated by the author, in reference to the experiments on the above subject by $M$. Schönbein, that long since MM. Chevallier, Girardin, Graham and Weppen, had noticed some of the interesting phænomena produced by it. But all these chemists made their experiments with perfectly purified animal charcoal; M. Schönbein, on the contrary, made use of ivory-black and coke, that is to say, of two varieties of carbon of complex constitution, and but little favourable for studying the action peculiar to carbon and for distinguishing it from that attributable to the foreign substances which accompany it. Ivory black, according to the analysis of $\mathrm{M}$. Braconnot, contains only 79 per cent. of carbon, the remaining 21 parts being composed of resinous matters, sulphate and phosphate of ammonia, chlorides, \&c., all of which are substances which can and must ever possess a decided influence on the results of the experiment. It is indeed true that the greater part of these impurities may be got rid of ; and it would be satisfactory to know that the precaution had been taken, but it is not mentioned that it was so. The same may be said of coke, which always contains, according to the manner in which it has been prepared, variable proportions of sulphur and of sulphurets, of which it is requisite to take notice.

M. Esprit is of opinion that the reduction of metallic solutions by carbon does not always occur; and he differs from $M$. Schönbein in supposing that bichloride of mercury is by its action reduced to protochloride. It is quite true that when a cold solution, even of bichloride of mercury, is treated with powdered charcoal, no trace of 
the bichloride is to be found in the filtered liquor: and at first it would be quite natural to suppose that reduction had occurred, and that protochloride of mercury would be found insoluble in the filter; it is however readily shown that this is not the case, as was proved, according to M. Esprit, by the following experiment:-a solution was made of $1 \mathrm{grm}$. of sublimate in $100 \mathrm{grms}$. of distilled water, and this solution was treated with $20 \mathrm{grms}$. of well-washed animal charcoal : the liquor, treated with potash, hydrosulphate of ammonia and iodide of potassium, did not indicate the presence of a mercurial salt; but on washing the charcoal which had been used in the experiment with a mixture of alcohol and æther, sublimate was rapidly dissolved; and in so large quantity, that when a tube was dipped into the solution, it gave a very distinct red precipitate with a solution of iodide of potassium.

This experiment, which the author repeated several times, and always with the same success, induced him to think that carbon does not act upon metallic solutions merely as a reducing agent, nor does he attribute it to the mere porosity of the charcoal, but he supposes that the metallic salt is retained by a peculiar force or special affinity. In studying the action of charcoal on metallic solutions, it is requisite to employ it quite free from sulphurets and calcareous salts, the presence of which complicates the operation, and does not allow of a proper estimate of the peculiar action of the charcoal.-Journ. de Chim. Méd., Septembre 1850.

\section{ON THE COPPER TEST FOR SUGAR. BY M. LASSAIGNE.}

It has been long known, according to the experiments of $M$. Frommherz, that tartrate of copper dissolved in a solution of potash is easily reduced when heated with glucose, and converted into suboxide of copper. The same author has stated that cane-sugar, which differs in composition from glucose, does not act upon this reagent. It is on these facts that $M$. Barreswil has founded his process for estimating the quantity of sugar.

The employment of this reagent is even indicated, in several recent chemical works, as capable of distinguishing between cane-sugar and glucose.

The alkaline solution of copper, employed as a test liquor, is prepared by two published methods; one by $M$. Barreswil, and the other by M. Poggiale. The first consists in dissolving with heat, in one-third of a litre of distilled water, 50 grammes of bitartrate of potash, and 40 grammes of carbonate of soda, and afterwards adding 30 grammes of powdered crystallized sulphate of copper; after boiling, allow the solution to cool, and lastly add 40 grammes of potash dissolved in one-fourth of a litre of water; it is made up a litre and again boiled. The second method, proposed by M. Poggiale to determine the presence of sugar of milk, which also reduces the oxide of copper, like glucose, consists in dissolving in 200 grammes of water 10 grammes of crystalline sulphate of copper, 10 grammes of 